\title{
Dioctadecyldimethylammonium:Monoolein Nanocarriers for Efficient in Vitro Gene Silencing
}

\author{
Ana Cristina Norberto Oliveira, ${ }^{\dagger, \ddagger}$ Thomas Frans Martens, ${ }^{\S, \|}$ Koen Raemdonck, ${ }^{\S}$ Renata Danielle Adati, ${ }^{\perp}$ \\ Eloi Feitosa, ${ }^{\perp}$ Cláudia Botelho, ${ }^{\#}$ Andreia Castro Gomes, ${ }^{\dagger}$ Kevin Braeckmans, ${ }^{\S, \|}$ \\ and Maria Elisabete Cunha Dias Real Oliveira*, \\ ${ }^{\dagger}$ CBMA (Center of Molecular and Environmental Biology), Department of Biology and ${ }^{\ddagger}$ CFUM (Center of Physics), Department of \\ Physics, University of Minho, Campus of Gualtar, 4710-057 Braga, Portugal \\ ${ }^{\S}$ Laboratory of General Biochemistry and Physical Pharmacy, Faculty of Pharmacy and "Center for Nano- and Biophotonics, Ghent \\ University, Harelbekestraat 72, 9000 Ghent, Belgium \\ ${ }^{\perp}$ Physics Department/IBILCE, São Paulo State University, 15054-000 São José do Rio Preto - SP, Brazil \\ ${ }^{\#}$ Institute for Biotechnology and Bioengineering, Centre of Biological Engineering, University of Minho, Campus of Gualtar, \\ 4710-057 Braga, Portugal
}

\section{Supporting Information}

ABSTRACT: This study describes a novel liposomal formulation for siRNA delivery, based on the mixture of the neutral lipid monoolein (MO) and cationic lipids of the dioctadecyldimethylammonium (DODA) family. The cationic lipids dioctadecyldimethylammonium bromide (DODAB) and chloride (DODAC) were compared in order to identify which one will most efficiently induce gene silencing. MO has a fluidizing effect on DODAC and DODAB liposomes, although it was more homogeneously distributed in DODAC bilayers. All MO-based
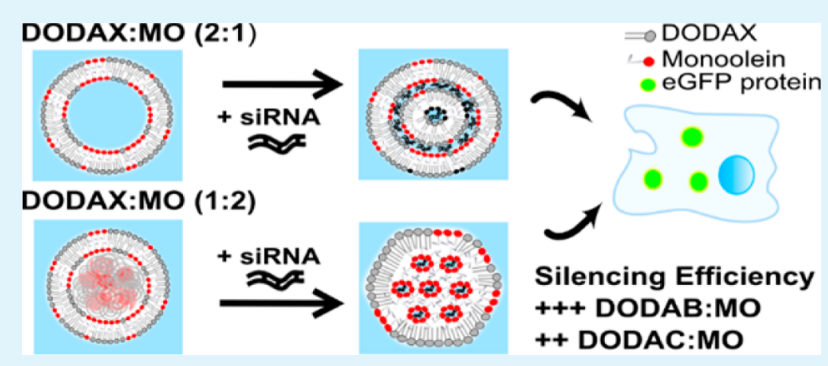
liposomal formulations were able to efficiently encapsulate siRNA. Stable lipoplexes of small size $(100-160 \mathrm{~nm})$ with a positive surface charge $(>+45 \mathrm{mV})$ were formed. A more uniform MO incorporation in DODAC:MO may explain an increase of the fusogenic potential of these liposomes. The siRNAlipoplexes were readily internalized by human nonsmall cell lung carcinoma (H1299) cells, in an energy dependent process. DODAB:MO nanocarriers showed a higher internalization efficiency in comparison to DODAC:MO lipoplexes, and were also more efficient in promoting gene silencing. MO had a similar gene silencing ability as the commonly used helper lipid 1,2-dioleyl3-phosphatidylethanolamine (DOPE), but with much lower cytotoxicity. Taking in consideration all the results presented, DODAB:MO liposomes are the most promising tested formulation for systemic siRNA delivery.

KEYWORDS: counterion, gene silencing, liposomes, monoolein, siRNA delivery

\section{INTRODUCTION}

The first findings regarding the RNA interference (RNAi) mechanism $^{1,2}$ opened a window of unique opportunities for scientists in the field of drug delivery. But even today, more than 10 years since RNAi technology was introduced, the success of siRNA therapy still depends on finding the best way to efficiently deliver siRNA to the target cells. ${ }^{3-6}$

The use of nanocarriers composed of lipid molecules has been one of the most explored alternatives to viral carriers for the delivery of nucleic acids to cells. ${ }^{4,5,7}$ Felgner et al. introduced cationic lipids as nucleic acid carriers in 1987, and since his pioneering work several liposomal formulations were developed for plasmid DNA (pDNA) delivery. ${ }^{9,10}$ The knowledge gained with pDNA gene delivery has been used to develop rational approaches for the production of suitable liposomal siRNA delivery systems. The success of the siRNA strategy is dependent on several factors such as nanocarriers' size, liposomal membrane fluidity, surface charge, stability, and ability to mediate efficient encapsulation of the nucleic acids. Reduced cytotoxicity, enhanced interaction, and internalization by target cells, as well as biodegradability, are also desirable characteristics for siRNA nanocarriers.

A helper lipid is often included in the liposomal formulation to improve the system's stability in physiologic conditions and/ or to facilitate structural changes to enhance endosomal escape, ${ }^{11,12}$ which is one of the most important bottlenecks in nucleic acid delivery. ${ }^{13}$ The neutral lipid 1,2-dioleyl-3phosphatidylethanolamine (DOPE) is typically introduced in the formulations as a helper lipid, due to its propensity to adopt nonlamellar structures. These structures are known to play a role in membrane fusion and destabilization of endosomal membranes, thereby allowing the release of the therapeutic

Received: February 6, 2014

Accepted: April 9, 2014

Published: April 9, 2014 
cargo into the cytosol. ${ }^{12,14}$ In fact, the intracellular lamellar to nonlamellar transition is thought to be a key factor governing the efficiency of lipid-based transfection agents. ${ }^{14}$ It is believed that the mechanism of nucleic acid release from lipoplexes involves the neutralization of cationic lipids by the cellular anionic lipids. ${ }^{15}$ This leads to an exchange of lipids between lipoplexes and the negatively charged membranes of endosomes, most likely by fusion of the endosomal membranes with the lipoplexes. The membrane destabilization process finally results in the release of the nucleic acids into the cell cytoplasm. Model membranes mimicking endosomal membranes have been used to evaluate the fusogenic ability of nanocarriers which gives an indication of the efficiency of nucleic acid release into the cell cytoplasm. ${ }^{16-18}$ The relationship between membrane fusion and lamellar to nonlamellar transition has long been recognized as a key factor in the development of lipid based nanocarriers. ${ }^{19}$ Not surprisingly, fusogenicity was found to correlate with transfection efficiency as well. ${ }^{20}$

The positively charged component of the liposomal formulations also has a strong impact on the transfection efficiency of the nanocarriers. ${ }^{9,21,22}$ Liposomes formed by lipids from the same family can exhibit different characteristics, as seen in the case of the dioctadecyldimethylammonium (DODA) family. ${ }^{23-25}$ Although dioctadecyldimethylammonium bromide (DODAB) and dioctadecyldimethylammonium chloride (DODAC) only differ in the nature of the counterion, its effect in the bilayer hydration significantly influences several properties like mean size and gel-to-liquid crystalline transition temperature. ${ }^{23-25,34-36}$ Therefore, it can be expected that when these lipids are mixed with other molecules, small differences like the counterion will influence the overall properties of the nanocarriers, and have a dramatic impact on the final lipoplex performance. $^{18}$

Recent work from our group has introduced MO as a helper lipid in liposomal formulations for pDNA delivery. Liposomes prepared with $\mathrm{DODAB}$ and $\mathrm{MO}$ were able to complex pDNA and effectively transfect Human Embryonic Kidney $293 \mathrm{~T}$ cells without inducing significant cytotoxicity. ${ }^{26,27}$ The evaluation of the lipid organization in DODAB:MO mixtures showed the existence of an inverted nonlamellar phase in excess $\mathrm{MO}$, while a lamellar organization prevails for MO fractions below $50 \%{ }^{28}$ The mechanism behind MO action is related not only to its ability to fluidize and stabilize the liposomal structures, but also to the fact that it forms nonlamellar inverted cubic or hexagonal phases, known to mediate the fusion processes. ${ }^{29}$ In effect, nonlamellar structures have already been reported to induce fusion between nanoparticles and endosomal membranes, thus enhancing the silencing efficiency of siRNA-nanoparticles. ${ }^{30}$

The aim of this work was to design a novel liposomal system for siRNA delivery with good fusogenicity and little or no cytotoxicity for therapeutic gene silencing. For that, we evaluated MO as a helper lipid, as well as the importance of the cationic lipid (DODAX, where $\mathrm{X}$ accounts for the $\mathrm{Cl}^{-}$or $\mathrm{Br}^{-}$counterion) on the physicochemical characteristics, cytotoxicity, cell uptake, and gene silencing efficiency of the liposomal nanocarriers in vitro.

\section{MATERIALS AND METHODS}

2.1. Materials. The reagents dioctadecyldimethylammonium bromide (DODAB), dioctadecyldimethylammonium chloride (DODAC), 1-monooleoyl-rac-glycerol (MO), cholesterol (Chol), bovine serum albumin (BSA), and dextran sulfate sodium salt were supplied by Sigma-Aldrich (Bornem, Belgium). 1,2-Dioleoyl-sn- glycero-3-phosphocholine (DOPC) was purchased from Corden Pharma (Liestal, Switzerland) and 1,2-dioleyl-3-phosphatidylethanolamine (DOPE) was obtained from Lipoid GMBH (Ludwigshafen, Germany). 1,2-Dioleoyl-sn-glycero-3-phospho-L-serine (DOPS), 1,2dioleoyl-sn-glycero-3-phosphatidylethanolamine-7-nitrobenzofurazan (NBD-PE) $\left(\lambda_{\text {exc }}=465 \mathrm{~nm} ; \lambda_{\mathrm{em}}=535 \mathrm{~nm}\right)$, and 1,2-dioleoyl-snglycero-phosphatidylethanolamine- $N$-(lissamine rhodamine B sulfonyl) ammonium salt (Rho-DOPE) $\left(\lambda_{\text {exc }}=545 \mathrm{~nm} ; \lambda_{\text {em }}=576 \mathrm{~nm}\right)$ were purchased from Avanti Polar Lipids (Alabaster, AL, USA). RPMI-1640 and Opti-MEM cell culture mediums, L-Glutamine, fetal bovine serum (FBS), Trypsin-EDTA solution, penicillin-streptomycin (5000 IU/ $\mathrm{mL}$ penicillin and $5000 \mu \mathrm{g} / \mathrm{mL}$ streptomycin), Geneticin, and phosphate-buffered saline (PBS) were purchased from Gibco (UK). LysoSensor Green was ordered from Molecular Probes (Merelbeke, Belgium). Hoechst no 33342, Lipofectamine RNAiMax, and SYBR Green were obtained from Invitrogen (Merelbeke, Belgium). Gel Loading Solution (all-purpose, native agarose) was purchased from Ambion, and MTT assay from Roche (Germany).

2.2. siRNA Duplexes. siRNA targeting the enhanced green fluorescent protein (siEGFP) and a universal negative control duplex (siCONTROL) were purchased from Eurogentec (Seraing, Belgium). siEGFP: sense strand = 5'-CAAGCUGACCCUGAAGUUCtt-3'; antisense strand $=5^{\prime}$-GAACUUCAGGGUCAGCUUGtt- ${ }^{\prime}$. siCONTROL: sense strand $=5^{\prime}$-UGCGCUACGAUCGACGAUGtt- ${ }^{\prime}$; antisense strand $=5^{\prime}$-CAUCGUCGAUCGUAGCGCAtt- ${ }^{\prime}$. Lower case letters represent $2^{\prime}$-deoxyribonucleotides. A Cy5-labeled siRNA duplex (Eurogentec, Seraing, Belgium) was used for confocal microscopy and uptake experiments. The lyophilized siRNAs were dissolved in DEPC-treated water to a concentration of $20 \mu \mathrm{M}$, aliquoted, and stored at $-20^{\circ} \mathrm{C}$ before use.

2.3. Preparation of Liposomes. Cationic liposomes composed of DODAX:MO (molar ratio 2:1 and molar ratio 1:2) were prepared by thin lipid film hydration followed by extrusion. Briefly, defined volumes of DODAC or DODAB and MO $(20 \mathrm{mM}$ stock solutions in ethanol) were placed in a round-bottomed flask and the solvent evaporated under vacuum at $40{ }^{\circ} \mathrm{C}$. The resultant lipid film was hydrated above the melting temperature of the cationic lipids $(>50$

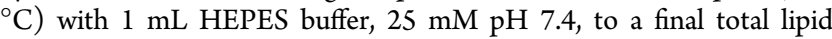
concentration of $5 \mathrm{mM}$. Finally, the liposomes were extruded at room temperature (RT) 11 times through a $100 \mathrm{~nm}$ pore sized polycarbonate membrane (Whatman, USA) using the Avanti Polar Lipids Mini-extruder.

2.4. Differential Scanning Calorimetry (DSC). DSC measurements were performed on a VP-DSC (MicroCal, Northampton, MA) calorimeter equipped with $0.542 \mathrm{~mL}$ twin cells for the reference and sample solutions. The total lipid concentration was maintained at 1 $\mathrm{mM}$ for all measurements, which were performed at the scan rate of 1 ${ }^{\circ} \mathrm{C} / \mathrm{min}$ and temperature range of $5-80{ }^{\circ} \mathrm{C}$. The gel-to-liquid crystalline transition temperature, $T_{\mathrm{m}}$, was determined as the temperature at the peak maximum. The enthalpy change associated with each transition $\left(\Delta H_{\mathrm{m}}\right)$ was calculated from integration of the thermograms using the equipment software (MicroCal Origin, v 7.0).

2.5. Lipid Mixing/Fusion Assay. Fluorescence resonance energy transfer (FRET) was used to determine the fusogenic potential of MO-based liposomes. FRET describes the energy transfer between two fluorophores (a donor (D) and a acceptor (A)), that is dependent not only on the overlap of the emission spectrum of the donor and the absorption spectrum of the acceptor, but also on the close localization between both species. ${ }^{31}$ The energy transfer efficiency $\left(\phi_{\text {FRET }}\right)$ between donor and acceptor can be an indication if lipid mixing/ fusion is occurring, because it implies the increase in the distance between donor and acceptor, leading to the increase in the average of the donor signal and in the signal loss of the acceptor fluorophore, and consequently decrease of $\phi_{\text {FRET }}$. In this study, FRET between NBD-PE (donor) and Rho-PE (acceptor) ${ }^{32}$ was used to monitor the process of lipid mixing/fusion between MO-based liposomes and model membrane liposomes (model endosomes). Model endosomes composed of DOPC:DOPE:DOPS:cholesterol (5:1:1:2) (mol:mol) were prepared by ethanolic injection as described elsewhere. ${ }^{26}$ The donor/acceptor (DA) model endosomes were labeled with $2 \mathrm{~mol} \%$ of 
NBD-PE and $1 \mathrm{~mol} \%$ of Rho-PE, and the donor (D) model endosomes were labeled with $2 \mathrm{~mol} \%$ of NBD-PE. Model endosomes were prepared at a final concentration of $1 \mathrm{mM}$ in MES-HEPES buffer, $20 \mathrm{mM}, \mathrm{pH} 7.2$ or $\mathrm{pH} 5.5$, to mimic early and late endosomes, respectively. For the fusion assays, $50 \mu \mathrm{M}$ of the DA or D model early or late endosomes, and $50 \mu \mathrm{M}$ of the MO-based liposomes were mixed. HEPES-MES buffer pH 5.5 or 7.2 was added to the mixture to make a final volume of $2.5 \mathrm{~mL}$. The fluorescence emission spectra $(480-700 \mathrm{~nm})$ was recorded in a Luminescence Spectrometer LS 50 (PerkinElmer) using a $\lambda_{\text {exc }}=460 \mathrm{~nm}$, with spectral bandwidths of 1 $\mathrm{nm}$. This wavelength corresponds to a point at which the spectra of the two species, with equal stoichiometry, cross each other (isosbestic point) such that the absorbance of the mixture of the two species at this wavelength remains invariant. Therefore, at this specific excitation wavelength, all the fluorescence intensity changes are exclusively dependent on energy transfer (FRET) (see Supporting Information, Figure S1). $\phi_{\text {FRET }}$ was determined according to eq 1 :

$$
\phi_{\text {FRET }}=1-\frac{F_{\mathrm{DA}}}{F_{\mathrm{D}}}
$$

where $F_{\mathrm{DA}}$ is the (DA) endosome fluorescence intensity (fluorescence of donor in the presence of acceptor), and $F_{\mathrm{D}}$ is the (D) endosome fluorescence intensity (fluorescence of the donor in the absence of the acceptor), at $\lambda_{\mathrm{em}}=530 \mathrm{~nm}$.

$\phi_{\text {FRET }}$ was quantified as a function of time after addition of MObased liposomes to the (D) and (DA) model endosomes.

2.6. Preparation of siRNA-Lipoplexes. siRNA-lipoplexes were prepared by incubating siRNA (diluted in HEPES buffer, $25 \mathrm{mM} \mathrm{pH}$ 7.4) with an equal volume of liposomes (in HEPES buffer, $25 \mathrm{mM} \mathrm{pH}$ $7.4)$ at the defined lipid concentration to form each charge ratio $( \pm)$. Lipoplexes were incubated for $20 \mathrm{~min}$ at RT before use.

2.7. Gel Electrophoresis Assay. siRNA-lipoplexes were prepared by mixing siCONTROL $(2.5 \mu \mathrm{M})$ with the appropriate concentration of liposomes to form siRNA-lipoplexes with DODAX:MO (2:1 and $1: 2$ ) at charge ratios $( \pm) 5,10,15$, and 20 , as described in section 2.6. siRNA $(1.25 \mu \mathrm{M})$ and siRNA-lipoplexes were loaded onto a $1 \%$ agarose gel TBE $1 \times$ using $1 \times$ loading dye. Electrophoresis was carried out under a constant electric field $(100 \mathrm{~V}, 15 \mathrm{~min})$ at RT and the gel was stained with SYBR Green before visualization with a UV Transilluminator 2000 (Bio Rad).

2.8. Dynamic Light Scattering (DLS) and Zeta $(\zeta)$ Potential. Mean size, polydispersity index (PDI), and surface charge of liposomes and siRNA-lipoplexes were determined by dynamic light scattering in a Zetasizer Nano ZS (Malvern, UK), equipped with Dispersion Technology Software (DTS). Measurements were made at $25{ }^{\circ} \mathrm{C}$. Samples were diluted to $1 \mathrm{mM}$ with HEPES buffer $25 \mathrm{mM}$ pH 7.4 before measurement and siRNA-lipoplexes were prepared with 200 $\mathrm{nM}$ siCONTROL. All results were based on intensity distributions.

2.9. Cell Lines and Culture Conditions. Human nonsmall cell lung carcinoma wild type cells (H1299 wt) and H1299 cells stably expressing enhanced green fluorescent protein (H1299 eGFP) were grown in RPMI 1640 cell culture medium supplemented with $1 \% \mathrm{~L}$ glutamine, $10 \% \mathrm{FBS}$, and $2 \%$ penicillin-streptomycin in a humidified incubator $\left(37^{\circ} \mathrm{C}\right.$ and $\left.5 \% \mathrm{CO}_{2}\right)$. Cells were passed every 3 days using $0.05 \%$ Trypsin-EDTA solution in order to maintain subconfluency. H1299 eGFP cells were treated with medium containing $1 \mathrm{mg} / \mathrm{mL}$ Geneticin once per month for selection.

2.10. Cytotoxicity Assay. The percentage of H1299 eGFP viable cells after incubation with siRNA-lipoplexes was determined by the MTT assay. Briefly, H1299 eGFP cells were seeded into 24-multiwell plates (SPL Life Sciences, Korea) at a density of $35 \times 10^{3}$ cells per well in complete cell culture medium. Immediately before siRNA-lipoplex addition, the culture medium was removed and replaced by OptiMEM. $100 \mu \mathrm{L}$ of siRNA-lipoplex solutions, prepared with $50 \mathrm{nM}$ siCONTROL, were added to each well and incubated for $4 \mathrm{~h}$ at $37^{\circ} \mathrm{C}$ and $5 \% \mathrm{CO}_{2}$. Lipofectamine RNAiMax lipoplexes (50 $\mathrm{nM}$ siCONTROL) were used as a control, and prepared in Opti-MEM according to manufacturer's instructions. After the $4 \mathrm{~h}$ incubation period, siRNA-lipoplexes in the supernatant were removed, and the medium was replaced by fresh cell culture medium. Cell viability was assessed with the MTT assay after $48 \mathrm{~h}$ according to the manufacturer's instructions.

2.11. Cellular Uptake Assay. Cellular uptake of siRNA-lipoplexes at $37{ }^{\circ} \mathrm{C}, 4{ }^{\circ} \mathrm{C}$, and upon addition of sodium azide was quantified by flow cytometry. H1299 eGFP cells were seeded into 24-multiwell plates at a density of $35 \times 10^{3}$ cells per well in complete cell culture medium. Immediately before siRNA-lipoplex addition, the culture medium was replaced by Opti-MEM. Cells were incubated with 100 $\mu \mathrm{L}$ siRNA-lipoplexes (final concentration of $50 \mathrm{nM}$ siRNA - $2 \%$ Cy5labeled siRNA and $98 \%$ siCONTROL) at $37{ }^{\circ} \mathrm{C}$ or at $4{ }^{\circ} \mathrm{C}$. For the control experiment at $4{ }^{\circ} \mathrm{C}$, cells were preincubated $15 \mathrm{~min}$ on ice before siRNA-lipoplexes were added. Lipofectamine RNAiMax lipoplexes (50 nM siCONTROL, 2\% Cy5-labeled siRNA) were prepared in Opti-MEM, according to manufacturer's instructions, and used as a control. After $4 \mathrm{~h}$ incubation, the cells were washed with PBS and a $0.1 \mathrm{mg} / \mathrm{mL}$ dextran sulfate solution was added for $5 \mathrm{~min}$ to remove noninternalized siRNA-lipoplexes attached to the cell exterior. Cells were further washed with PBS and detached with trypsin $(0.25 \%$ Trypsin-EDTA), which was then neutralized with $1 \mathrm{~mL}$ complete cell culture medium. After centrifugation ( $1400 \mathrm{rpm}, 7 \mathrm{~min})$, the cell pellet was resuspended in $300 \mu \mathrm{L}$ flow buffer (1\% BSA and $0.1 \%$ sodium azide in PBS) and kept on ice until analysis on a Beckman Coulter Cytomics FC500 flow cytometer equipped with an argon laser (excitation of Cy5 at $633 \mathrm{~nm}$ ). Uptake experiments were performed in triplicate and $10 \times 10^{3}$ cells were considered for each sample. The percentage of cellular internalization was determined as the percentage of positive cells, defined by a threshold set to have $0.5 \%$ of positive cells on the control sample (cells not incubated with siRNAlipoplexes) at $37{ }^{\circ} \mathrm{C}$. The same procedure was followed for the treatment with sodium azide, after a $30 \mathrm{~min}$ preincubation period with $100 \mathrm{mM}$ sodium azide.

2.12. EGFP Silencing. EGFP gene silencing was evaluated by flow cytometry. H1299 eGFP cells were seeded on 24-multiwell plates at a density of $35 \times 10^{3}$ cells per well in complete cell culture medium. siRNA-lipoplexes were prepared with siRNA negative control (siCONTROL) or eGFP targeting siRNA (siEGFP) (10 nM or 50 nM siRNA) in HEPES buffer. Immediately before transfection, the culture medium was removed and replaced by Opti-MEM. $100 \mu \mathrm{L}$ aliquots of siRNA-lipoplex solutions were added to each well, and after $4 \mathrm{~h}$ incubation at $37{ }^{\circ} \mathrm{C}$ and $5 \% \mathrm{CO}_{2}$, noninternalized siRNAlipoplexes were removed and Opti-MEM replaced by fresh cell culture medium. Lipofectamine RNAiMax lipoplexes (with siCONTROL and siEGFP) were prepared in Opti-MEM, according to manufacturer's instructions, and used as control. Cells were prepared for analysis as described for the cellular uptake assay, with excitation of eGFP at 488 $\mathrm{nm}$. Transfections were performed in triplicate and $20 \times 10^{3}$ cells were considered for each sample. The percentage of downregulation was expressed according to eq 2 :

$$
\text { \%Downregulation }=\left(1-\frac{\text { siEGFP }}{\text { siCONTROL }}\right) \times 100
$$

where siEGFP and siCONTROL represent the mean EGFP fluorescence intensity of cells treated with siRNA-lipoplexes prepared with siEGFP and siCONTROL, respectively.

2.13. Microscopy Studies. H1299 wild type cells were cultured on glass bottomed $35 \mathrm{~mm}$ cell culture dishes (Greiner, Germany) at a cell density of $1.25 \times 10^{5}$ cells per dish. Immediately before siRNAlipoplex addition, cell culture medium was replaced by Opti-MEM. Cells were incubated with $100 \mu \mathrm{L}$ siRNA-lipoplexes (final concentration of $50 \mathrm{nM}$ siRNA - 50\% Cy5-labeled siRNA and 50\% siCONTROL) at $37^{\circ} \mathrm{C}$. Lipofectamine RNAiMax lipoplexes were prepared in Opti-MEM, and used as a control. After $4 \mathrm{~h}$ incubation, cells were washed with PBS and a $0.1 \mathrm{mg} / \mathrm{mL}$ dextran sulfate solution was added for $5 \mathrm{~min}$ to remove the noninternalized siRNA-lipoplexes. Cells were washed with PBS and complete cell culture medium was added. Samples were observed with a Nikon C1 confocal laser scanning microscope (Nikon Belux, Brussels, Belgium) equipped with a Plan Apo VC 60× 1.2 NA water immersion objective lens. 
Endolysosomal staining was made by $1 \mathrm{~h}$ incubation with LysoSensor Green $(1 \mu \mathrm{M})$, while 15 min incubation with Hoechst no 33342 (1 $\mu \mathrm{M})$ was used for nucleus staining.

2.14. Statistical Analysis. Statistical analysis was performed with GraphPad Prism 5.0 software, using the one-way ANOVA test, followed by a Dunnett's multiple comparison test. Results were expressed as mean \pm standard deviation (S.D.), and $p<0.05$ was considered to be statistically significant.

\section{RESULTS AND DISCUSSION}

3.1. Physicochemical Characterization of DODAX:MO Liposomes and siRNA-Lipoplexes. 3.1.1. Differential Scanning Calorimetry (DSC) Assay. In this study we used differential scanning calorimetry (DSC) to evaluate the effect of $\mathrm{MO}$ on the gel-to-liquid crystalline phase transition temperature $\left(T_{\mathrm{m}}\right)$ and on the enthalpy change $\left(\Delta H_{\mathrm{m}}\right)$ of DODAX:MO mixtures. $T_{\mathrm{m}}$ gives indications about the liposomal membrane fluidity and overall lipid organization, which are extremely important characteristics for the success of nucleic acid encapsulation and good transfection efficiency of lipoplexes. ${ }^{33}$

Figure 1 shows the thermal behavior of DODAX:MO mixtures at different molar ratios. As can be seen in Figure 1A,

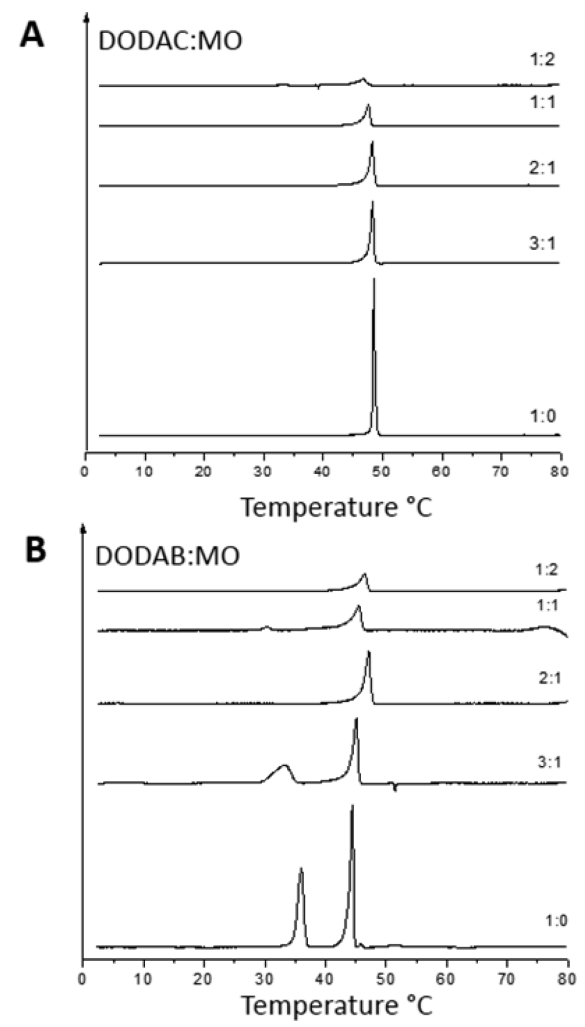

Figure 1. Comparative effects of MO on the DSC thermograms of DODAC/B $(1 \mathrm{mM})$ obtained in the heating mode, at scan rate $1{ }^{\circ} \mathrm{C} /$ min. (A) DODAC:MO mixtures; (B) DODAB:MO mixtures.

the peaks associated with the $T_{\mathrm{m}}$ became less well-defined with the increase of the amount of MO incorporated in DODAC bilayers. Nevertheless, there is no clear shift of $T_{\mathrm{m}}$ to lower temperatures, and $T_{\mathrm{m}}$ is still detected for the highest percentage of MO tested ( $66 \% \mathrm{~mol}: \mathrm{mol})$. The presence of $T_{\mathrm{m}}$ indicates that rigid bilayers are still present in all DODAC:MO formulations.
As described before, ${ }^{23}$ DODAB presents a pretransition temperature $\left(T_{\mathrm{p}}\right)$ due to the tilting of the DODAB chains prior to the melting temperature. Figure $1 \mathrm{~B}$ shows that the first effect of $\mathrm{MO}$ incorporation was in the $T_{\mathrm{p}}$ of DODAB. With $25 \%$ (mol:mol) MO (DODAB:MO (3:1)), $T_{\mathrm{p}}$ became broader and less intense, and a further increase in MO (DODAB:MO (2:1)) completely abolished $T_{\mathrm{p}}$. Nevertheless, in the formulation DODAB:MO (1:1) (50\% MO (mol:mol)), $T_{\mathrm{p}}$ appeared again, which points to some phase separation between DODAB and MO (Figure 1B).

Even though DODAC and DODAB lipids only differ chemically in the counterion, when dispersed in solution they form vesicles with different thermotropic behavior. ${ }^{23,24,34}$ The fact that $\mathrm{Cl}^{-}$and $\mathrm{Br}^{-}$ions have different sizes in solution (average number of bound water molecules of $2.0 \mathrm{for}^{-}$and 1.5 for $\mathrm{Br}^{-35,36}$ ) indicates that the hydrated $\mathrm{Cl}^{-}$is larger than the hydrated $\mathrm{Br}^{-}$. Therefore, $\mathrm{Cl}^{-}$ion cannot be as closely associated with the cationic headgroup of the lipid as $\mathrm{Br}^{-}$ion, making the neutralization of the positive charges of the cationic headgroup less effective with $\mathrm{Cl}^{-}$than with $\mathrm{Br}^{-}$. This results in larger electrostatic repulsions between the head groups of DODAC bilayers, not only within the aggregates, but also between DODAC liposomes. Moreover, it was reported that, for more hydrated counterions (as the case of $\mathrm{Cl}^{-}$in DODAC), a dual behavior is observed: the presence of a less ordered polar region due to strong repulsive interactions between the head groups of the lipids, and stiffer hydrocarbon chains to avoid contact of the hydrophobic region with the aqueous media. ${ }^{35}$ As a result, although DODAB forms bilayers more densely packed at the headgroup region than DODAC, ${ }^{25,36}$ DODAC vesicles exhibit higher $T_{\mathrm{m}}$ values and smaller sizes than DODAB vesicles. $T_{\mathrm{m}}$ is related, in a complex way, to the energy required to dehydrate the polar headgroup together with the associated counterions, which in turn depends on the interaction of the counterions with the surrounding aqueous media.

Tables 1 and 2 show, in more detail, the $T_{\mathrm{m}}$ and $\Delta H_{\mathrm{m}}$ of the neat cationic lipids and DODAX:MO (2:1 and 1:2) mixtures.

Table 1. Gel-to-Liquid Crystalline Transition Temperature $\left(T_{\mathrm{m}}\right)$ and Variation in Enthalpy $\left(\Delta H_{\mathrm{m}}\right)$ of DODAX:MO, as Determined by DSC in the Heating Mode

\begin{tabular}{lcrrrrrr} 
& & \multicolumn{2}{c}{ DODAC:MO } & & \multicolumn{2}{c}{ DODAB:MO } \\
\cline { 3 - 4 } \cline { 7 - 8 } & DODAC & $(2: 1)$ & $(1: 2)$ & & DODAB $^{a}$ & $(2: 1)$ & $(1: 2)$ \\
$T_{\mathrm{m}}\left({ }^{\circ} \mathrm{C}\right)$ & 48.6 & 48.3 & 46.7 & 44.4 & 47.1 & 46.5 \\
$\Delta H_{\mathrm{m}}(\mathrm{kJ} / \mathrm{mol})$ & 41.5 & 29.2 & 8.8 & 47.4 & 25.4 & 11.6 \\
$\Delta T_{1 / 2}\left({ }^{\circ} \mathrm{C}\right)$ & 0.3 & 0.8 & 1.7 & 0.59 & 0.94 & 1.51
\end{tabular}

${ }^{a}$ Neat DODAB also presents a pretransition temperature $T_{\mathrm{p}}=36.0$ ${ }^{\circ} \mathrm{C}, \Delta T_{1 / 2}=1.10{ }^{\circ} \mathrm{C}$ with $\Delta H_{\mathrm{m}}=33.5 \mathrm{~kJ} / \mathrm{mol}$.

Table 2. Gel-to-Liquid Crystalline Transition Temperature $\left(T_{\mathrm{m}}\right)$ and Variation in Enthalpy $\left(\Delta H_{\mathrm{m}}\right)$ of DODAX:MO, as Determined by DSC in the Cooling Mode

\begin{tabular}{lrrrrrrc} 
& & \multicolumn{2}{c}{ DODAC:MO } & & \multicolumn{2}{c}{ DODAB:MO } \\
\cline { 3 - 4 } & DODAC & $(2: 1)$ & $(1: 2)$ & DODAB $^{a}$ & $(2: 1)$ & $(1: 2)$ \\
$T_{\mathrm{m}}\left({ }^{\circ} \mathrm{C}\right)$ & 43.2 & 42.8 & 41.0 & 39.8 & 41.4 & 40.7 \\
$\Delta H_{\mathrm{m}}(\mathrm{kJ} / \mathrm{mol})$ & 41.5 & 28.8 & 9.3 & 41.5 & 28.3 & 13.1 \\
$\Delta T 1 / 2\left({ }^{\circ} \mathrm{C}\right)$ & 0.8 & 1.0 & 1.2 & 0.42 & 0.98 & 0.98
\end{tabular}

${ }^{a}$ Neat DODAB also presents a pretransition temperature $T_{\mathrm{p}}=10.0$

${ }^{\circ} \mathrm{C}, \Delta T_{1 / 2}=10.1{ }^{\circ} \mathrm{C}$ with $\Delta H_{\mathrm{m}}=17.7 \mathrm{~kJ} / \mathrm{mol}$. 
Table 3. Physicochemical Characterization of DODAX:MO Liposomes and siRNA-Lipoplexes ${ }^{a}$

\begin{tabular}{|c|c|c|c|c|c|c|}
\hline & \multicolumn{3}{|c|}{ liposomes } & \multicolumn{3}{|c|}{ lipoplexes } \\
\hline & mean size $(\mathrm{nm})$ & PDI & $\zeta$-potential $(\mathrm{mV})$ & mean size $(\mathrm{nm})$ & PDI & $\zeta$-potential $(\mathrm{mV})$ \\
\hline DODAC:MO (2:1) & $101 \pm 2$ & $0.120 \pm 0.016$ & $55 \pm 1$ & $103 \pm 1$ & $0.089 \pm 0.007$ & $47 \pm 1$ \\
\hline DODAB:MO (2:1) & $134 \pm 3$ & $0.156 \pm 0.008$ & $59 \pm 1$ & $158 \pm 1$ & $0.150 \pm 0.017$ & $54 \pm 1$ \\
\hline DODAC:MO (1:2) & $104 \pm 2$ & $0.082 \pm 0.006$ & $57 \pm 1$ & $110 \pm 1$ & $0.068 \pm 0.015$ & $51 \pm 1$ \\
\hline DODAB:MO (1:2) & $108 \pm 3$ & $0.061 \pm 0.023$ & $60 \pm 2$ & $120 \pm 3$ & $0.065 \pm 0.017$ & $52 \pm 1$ \\
\hline
\end{tabular}

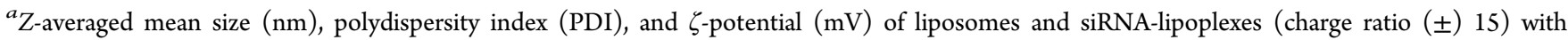
siRNA final concentration in lipoplexes of $200 \mathrm{nM}$. Data are presented as mean \pm S.D.

DODAX:MO (2:1)

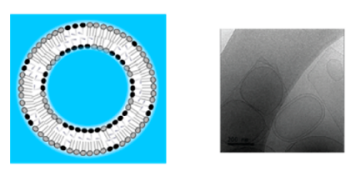

DODAX:MO (1:2)

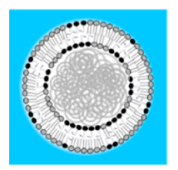

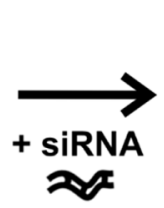
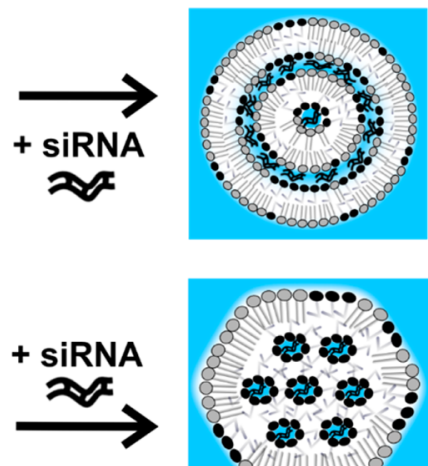

Prevalence

of lamellar

structures

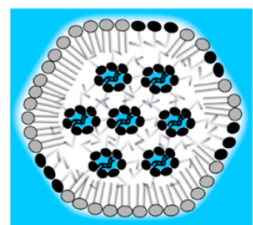

Prevalence

of non-lamellar

structures

Figure 2. Schematic representation of the proposed model for the structures of DODAX:MO siRNA-lipoplexes. Cryo-TEM images adapted from ref 28.

The heating and cooling DSC results are in agreement with the literature, ${ }^{23,24,28,34}$ with neat DODAC vesicles exhibiting higher $T_{\mathrm{m}}$ than neat DODAB (48.6 and $44.4^{\circ} \mathrm{C}$ in the heating and 43.2 and $39.8{ }^{\circ} \mathrm{C}$ in the cooling, respectively).

The inclusion of MO had a different effect on the two types of liposomes: the presence of $\mathrm{MO}$ decreased the $T_{\mathrm{m}}$ for DODAC liposomes, while in the case of DODAB formulations this effect was dependent on the MO concentration. In the presence of $33 \% \mathrm{MO}$ (mol:mol) the $T_{\mathrm{m}}$ of DODAB liposomes increased from 44.4 to $47.1{ }^{\circ} \mathrm{C}$, but the addition of $66 \% \mathrm{MO}$ (mol:mol) resulted in a decrease to $46.5{ }^{\circ} \mathrm{C}$ (Table 1). Even so, the $T_{\mathrm{m}}$ is higher for DODAC in comparison to DODAB vesicles. The same trend was observed in the cooling mode (Table 2).

The increase in $T_{\mathrm{m}}$ of DODAB:MO (2:1) and (1:2) may be related to the asymmetric distribution of $\mathrm{MO}$ in the bilayer, leading to the formation of lipid domains rich in MO (more fluid) and rich in DODAB (more rigid). MO tends to abolish the pretransition temperature $T_{\mathrm{p}}$ of $\mathrm{DODAB}$, similar to what has been observed with cholesterol at low concentrations. ${ }^{37,38}$

The DSC results clearly indicate that DODAC and DODAB systems behave differently in the presence of MO. The comparison between the transition temperatures is complex and should be made carefully. The initial shift on $T_{\mathrm{m}}$ and disappearance of $T_{\mathrm{p}}$ observed for DODAB:MO (2:1) is also described for other systems, namely, for the incorporation of cholesterol into bilayer membranes. ${ }^{38}$ It was shown that with $50 \%$ cholesterol there was still evidence of the gel-to-liquid crystalline transition. For the mixtures DODAX:MO, $T_{\mathrm{m}}$ could be measured even with $66 \% \mathrm{MO}$ (mol:mol), although a decrease in the $T_{\mathrm{m}}$ value was observed for both formulations, indicating that $\mathrm{MO}$ increases fluidity of the lipid bilayers.

It is known that $\Delta H_{\mathrm{m}}$ gives an indication of the number of molecules that contribute to the $T_{\mathrm{m}}$ value. As can be seen in Tables 1 and 2, the incorporation of $\mathrm{MO}$ also had an effect on
$\Delta H_{\mathrm{m}}$, even higher than on $T_{\mathrm{m}}$. The decrease in $\Delta H_{\mathrm{m}}$ suggests that fewer molecules contribute to the gel-to-liquid crystalline transition when the MO content was increased. Nevertheless, the effects of MO were more pronounced for the DODAC:MO mixtures. The decrease in $\Delta H_{\mathrm{m}}$ for DODAB:MO varying from 2:1 to $1: 2$ was $13.8 \mathrm{~kJ} / \mathrm{mol}$, while for DODAC:MO varying from 2:1 to $1: 2$ was $20.4 \mathrm{~kJ} / \mathrm{mol}$ (Table 1 ). This result suggests that the incorporation of $\mathrm{MO}$ was more homogeneous in the DODAC than in DODAB bilayers, which can be explained by the fact that DODAC bilayers have less tight polar head groups, where MO can be more easily incorporated and homogeneously distributed. On the other hand, DODAB polar head groups are more tightly packed and hinder the integration of $\mathrm{MO}$ within the $\mathrm{DODAB}$ bilayers. Altogether, these results demonstrate that the helper lipid has the ability to fluidize the liposomal membranes, although to a different extent. This fact reinforces the idea that DODAB:MO and DODAC:MO liposomes have a different lipid structural organization.

3.1.2. Dynamic Light Scattering (DLS) Assay. The different formulations were fully characterized in terms of size and surface charge, as demonstrated in Table 3.

DODAX:MO liposomes prepared by lipid film hydration followed by extrusion have a uniform size distribution (PDI < 0.2 ). The DODAB:MO liposomes have slightly higher mean size than DODAC:MO liposomes, which is in accordance with the literature. ${ }^{23,24}$ This difference in size is a consequence of the different counterions. $\mathrm{Br}^{-}$is less hydrated and has a smaller headgroup area than $\mathrm{Cl}^{-}$, originating liposomes with lower curvatures. $^{25,36}$ The strong electrostatic repulsions that occur between DODAC head groups increase the curvature of the aggregates, originating liposomes with smaller sizes. ${ }^{35,36}$

The combination of $33 \%$ ( $\mathrm{mol}: \mathrm{mol}$ ) or $66 \%$ (mol:mol) MO with DODAC did not affect the size of the DODAC-based nanoparticles, although a reduction of more than $24 \%$ on the 


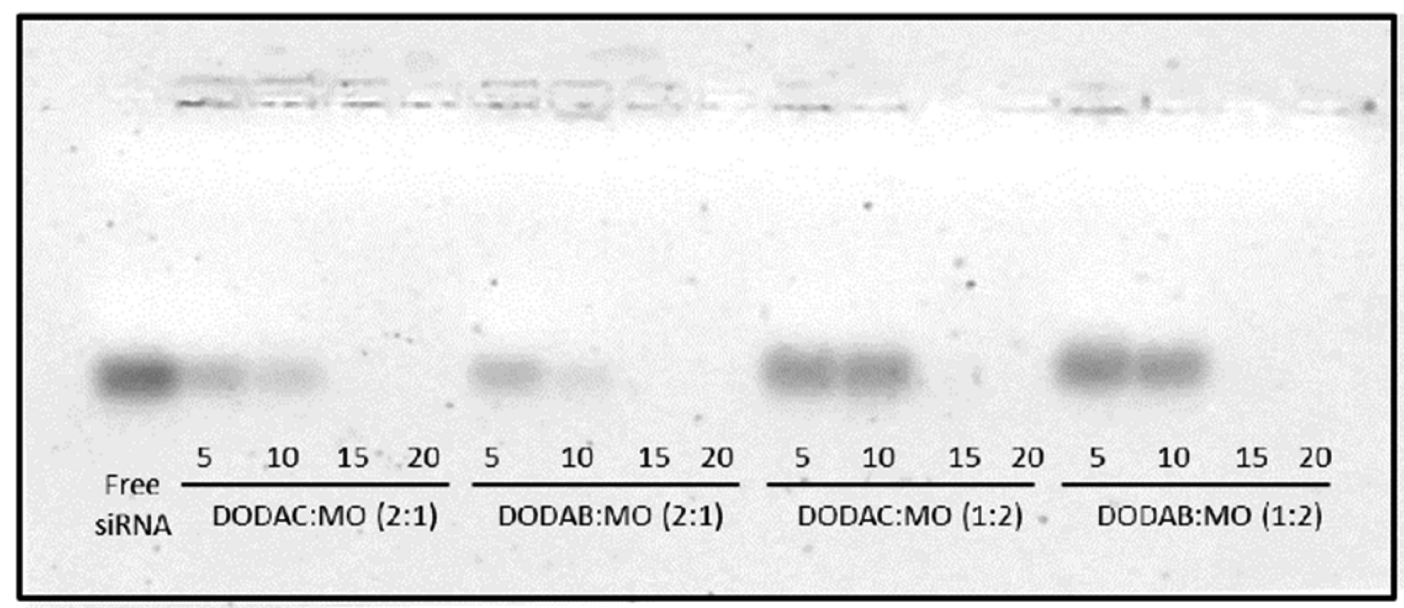

Figure 3. Gel electrophoresis of siRNA-lipoplexes prepared at charge ratios $( \pm)$ 5, 10, 15, and 20, in HEPES buffer (25 mM, pH 7.4), with 1.25 $\mu \mathrm{M}$ final siRNA concentration.

mean size was observed from DODAB:MO (2:1) to DODAB:MO (1:2) liposomes and lipoplexes.

A significantly different mean size was not observed for nanocarriers with more MO (DODAX:MO (1:2)), probably because $\mathrm{MO}$ is preferentially localized in the interior of the lipidic structures, due to its natural negative curvature, ${ }^{39}$ making the size of DODAX:MO (1:2) more similar and less polydisperse.

Based on the DSC and DLS results (Figure 1, Tables 1, 2, and 3), a model representing the structure of the DODAX:MO siRNA-lipoplexes is suggested in Figure 2.

This hypothesis is based on the fact that, for DODAB-rich formulations (DODAB:MO (2:1)), MO is distributed in the lamellar phase of $\mathrm{DODAB}$, forming MO-rich domains; and for MO-rich formulations (DODAB:MO (1:2)), DODAB and MO self-assemble, respectively, into lamellar and nonlamellar phases. $^{28}$ Therefore, for DODAX-enriched formulations (DODAX:MO (2:1)), where lamellar liposomes are prevalent, the encapsulation of siRNA will maintain the lamellar phase, and a multilamellar structure will predominantly be formed, with the anionic nucleic acids sandwiched between the lipid membranes. For MO-enriched formulations (DODAX:MO $(1: 2)$ ), where a coexistence of lamellar and nonlamellar aggregates was observed, ${ }^{28}$ the encapsulation of siRNA will originate a DODAX lamellar phase enclosing the MO nonlamellar phases, where the siRNA will preferentially localize. Several biophysical studies ${ }^{30,40-42}$ also support two possible models for the structure of lipoplexes, depending on the percentage of helper lipid. Therefore, as represented in Figure 2, distinct nanoscale structures of siRNA-lipoplexes might be formed according to the DODAX:MO liposomes used to encapsulate the siRNA.

Both MO-based liposomes, and siRNA-lipoplexes prepared at charge ratio $( \pm) 15$, exhibited highly positive $\zeta$-potentials: > $+55 \mathrm{mV}$ and $>+45 \mathrm{mV}$, respectively (Table 3 ). The presence of a high concentration of MO ( $66 \% \mathrm{~mol}: \mathrm{mol})$ did not reduce the surface charge of either liposomes or lipoplexes, reinforcing the idea that $\mathrm{MO}$ is located preferably inside the nanostructures, as previously observed for other MO enriched systems. ${ }^{28,43}$

Nanocarriers' physicochemical properties largely govern the success of every gene therapy strategy, and systemic applications demand small nanocarriers, to prevent clogging of capillaries, but also to allow them to extravasate through the fenestrated endothelium. ${ }^{44,45}$ Size and surface charge also determine colloidal stability and influence interaction with cellular membranes and consequent cellular internalization. The physicochemical characteristics of the produced siRNAlipoplexes were found to be promising for systemic delivery and interaction with the cells.

3.1.3. siRNA Complexation Efficiency Assay. In spite of the differences that MO induced on $T_{\mathrm{m}}$ and $\Delta H_{\mathrm{m}}$ of DODAC:MO and DODAB:MO liposomes (Tables 1 and 2), all liposomal formulations achieved good complexation efficiency at charge ratio $( \pm) 15$ (Figure 3 ). Even though MO induced a different degree of fluidity on the liposomes, it did not affect their siRNA complexation ability. The highly positive surface charge of the liposomes was sufficient for an effective siRNA complexation.

In subsequent experiments, lipoplexes prepared at charge ratio $( \pm) 15$ were used, to ensure maximum siRNA loading.

3.2. Lipid Mixing Assay. Nanocarriers' ability to destabilize and fuse with membranes can be determinant for endosomal escape and efficient gene silencing. ${ }^{46}$ For the study of the fusogenic ability of DODAX:MO liposomes, a FRET assay, using the pair NBD-PE (donor) and Rho-PE (acceptor) (Supporting Information, Figure S1), was performed to evaluate the lipid mixing/fusion events between MO-based liposomes and the model endosomes, at neutral and acidic conditions.

FRET has been frequently used not only to detect lipid mixing and fusion events, but also to study nucleic acid complexation/destabilization processes. ${ }^{16-18,32,47}$ The fluorescence intensities were used to calculate the energy transfer efficiency $\left(\phi_{\mathrm{FRET}}\right)$ (Supporting Information, Figure S2).

MO-based liposomes did not promote a markedly fusogenic effect compared to other systems, ${ }^{16,18}$ although a reduction in FRET signal could still be detected at both $\mathrm{pH} 7.2$ and $\mathrm{pH} 5.5$ (Figure 4A and B). Surprisingly, the higher MO content in DODAX:MO (1:2) did not provide higher fusogenic capacity to liposomes. This result can be another indication that $\mathrm{MO}$ is preferentially located inside of the lipidic structures, and is not available to interact with the model endosomes to promote fusion.

DODAC:MO formulations were able to fuse at higher extent than DODAB:MO, likely a result of the more homogeneous integration of $\mathrm{MO}$ in DODAC bilayers than in DODAB bilayers (Figure 1 and Tables 1 and 2), supporting the $\mathrm{MO}$ 
$\rightarrow$ DODAC:MO (2:1) - $\rightarrow$ DODAC:MO (1:2)

$\rightarrow$ DODAB:MO (2:1) -

\section{A}

pH 7.2

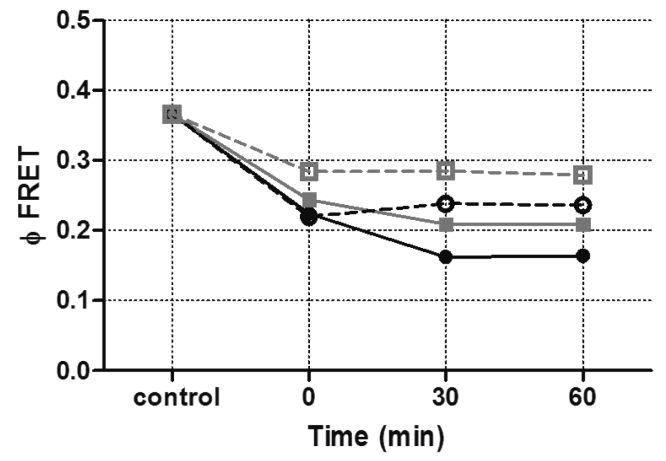

B

pH 5.5

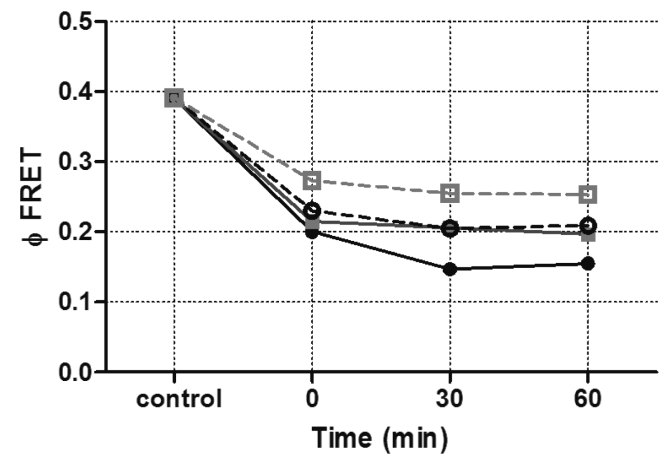

Figure 4. Ability of MO-based liposomes to destabilize model endosomal membranes, as assessed by FRET assay. (A) $\phi_{\text {FRET }}$ after incubation of MO-based endosomes with model early endosomes $(\mathrm{pH}$ 7.2). (B) $\phi_{\text {FRET }}$ after incubation of MO-based endosomes with model late endosomes ( $\mathrm{pH}$ 5.5). Control-model early or late endosomes in the absence of MO-based liposomes, which corresponds to maximum $\phi_{\text {FRET }}$.

fusogenic potential. DODAX:MO (2:1) slightly decreased $\phi_{\text {FRET }}$ over time, suggesting that the lipid mixing process proceeds gradually over time. The acidification of the environment led to a small decrease on $\phi_{\mathrm{FRET}}$ for DODAX:MO (1:2) (Figure 4A compared to B), where MO was present at a higher percentage.

Lipid mixing between positively and negatively charged membranes is favored by electrostatic interactions. Therefore, the occurrence of lipid interactions between MO-based liposomes and negatively charged model endosomes, although not to a great extent, were expected, and confirmed in Figure 4. As anticipated, differences in the fusogenic capacity were found between DODAC and DODAB:MO liposomes, due to the different $\mathrm{MO}$ incorporation in the cationic bilayers.

3.3. Cytotoxicity, Transfection Efficiency, and Cellular Internalization of DODAX:MO siRNA-Lipoplexes. An MTT assay was used to evaluate the impact of siRNAlipoplexes on the metabolic activity of H1299 eGFP cells, $48 \mathrm{~h}$ after incubation. In Figure $5 \mathrm{~A}$ it is possible to observe the cytotoxicity induced by Lipofectamine RNAiMax, DODAC:$\mathrm{MO}$, and DODAB:MO lipoplexes at charge ratios $( \pm) 10,15$, and 20, prepared with $50 \mathrm{nM}$ siRNA (maximum siRNA concentration used for the gene silencing assays, in Figure 5B).

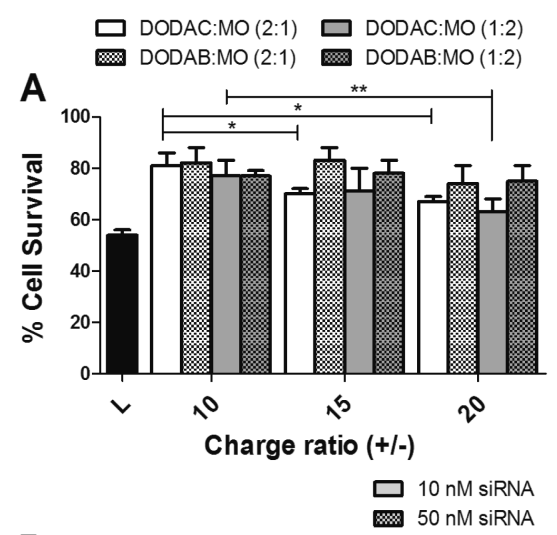

B
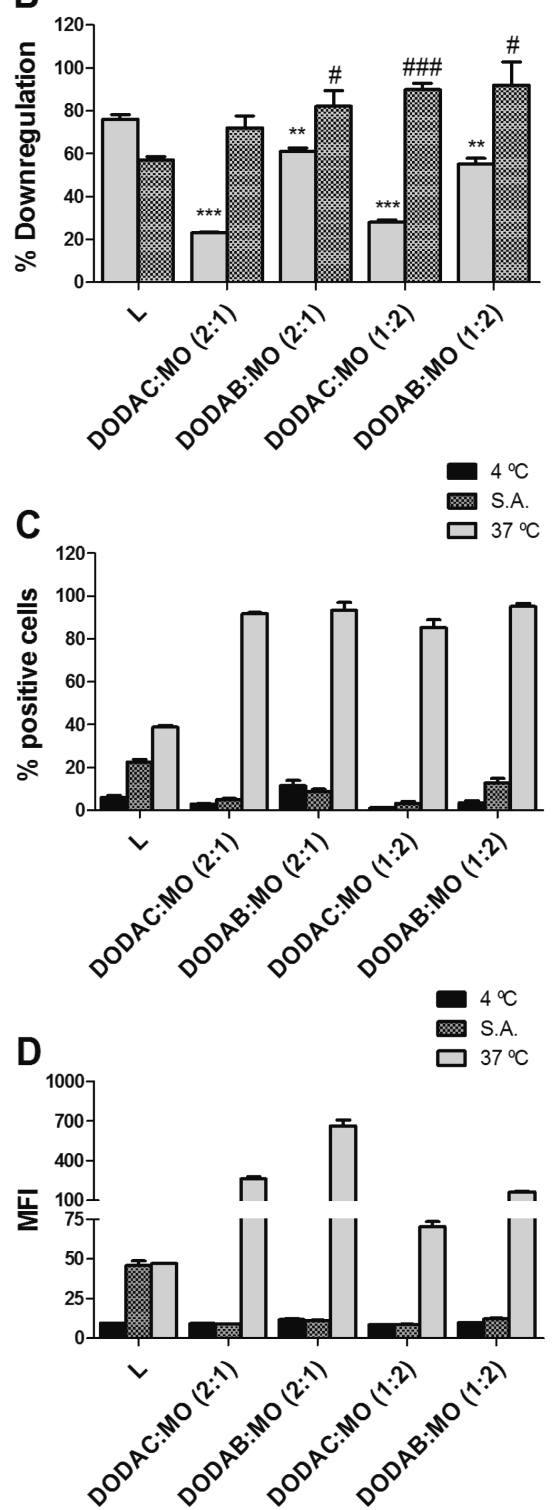

Figure 5. In vitro evaluation of siRNA-lipoplexes. (A) Metabolic cytotoxicity induced by siRNA-lipoplexes on H1299 eGFP cells, as determined by MTT assay, $48 \mathrm{~h}$ after incubation. (B) Evaluation of eGFP silencing by siRNA-lipoplexes, $48 \mathrm{~h}$ after incubation, as determined by flow cytometry. (C and D) Cellular uptake of siRNA-lipoplexes, after a $4 \mathrm{~h}$ incubation period with H1299 eGFP, as determined by flow cytometry. The percentage of cellular uptake (C) and the mean fluorescence intensity (D) are shown. L Lipofectamine RNAiMax. S.A. - Sodium Azide. MFI - Mean 
Figure 5. continued

Fluorescence Intensity. Results are expressed as mean \pm SD. The ANOVA statistical test was performed, followed by a Dunnett's multiple comparison test. $* p<0.05, * * p<0.01$, and $* * * p<0.005$ for

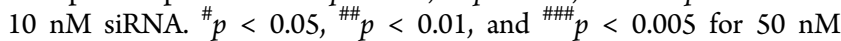
siRNA. The differences against Lipofectamine RNAiMax are indicated.

The commercial reagent Lipofectamine RNAiMax induced the strongest cytotoxic response, while MO-based siRNA lipoplexes were better tolerated by the cells. Interestingly, although having very similar physicochemical characteristics (Figure 1 and Tables 1 and 2), DODAB:MO lipoplexes were found to be less cytotoxic than DODAC:MO lipoplexes, especially for higher charge ratios. Besides the study of the cytotoxicity of the lipoplexes, the highly charged liposomes used in these formulations could be a matter of concern in terms of cellular toxicity. Therefore, additional tests were performed to further clarify the mechanism of cytotoxicity associated with the DODAX:MO liposomes. The liposomal formulations with higher percentage of cationic lipids (DODAX:MO (2:1)) were chosen, and the effect of the counterion was additionally evaluated (Supporting Information, Figure S3). A similar cytotoxic response was observed for DODAX:MO liposomes, with DODAC:MO inducing higher metabolic cytotoxicity than DODAB:MO liposomes. Nevertheless, it was also possible to conclude that for the liposome concentrations used to form the siRNA-lipoplexes, the cytotoxic effect is not significant, which is thus related with the low cytotoxicity observed for the siRNAlipoplexes (Figure 5A).

Figure $5 \mathrm{~B}$ reveals the silencing efficiency of MO-based lipoplexes, as determined by the extent of eGFP downregulation in H1299 eGFP cells. When prepared with $10 \mathrm{nM}$ siRNA, DODAB:MO (2:1) and (1:2) lipoplexes led to higher transfection efficiencies compared to DODAC:MO $(2: 1)$ and (1:2). Of those formulations, DODAB:MO $(2: 1)$ was the most efficient in promoting eGFP silencing in H1299 eGFP cells (61\% downregulation), followed by DODAB:MO (1:2) (55\%) and DODAC:MO lipoplexes $(<30 \%)$. There was a decrease in the Lipofectamine RNAiMax silencing efficiency when the concentration of siRNA was increased to $50 \mathrm{nM}$, as a consequence of the high toxicity of this system (Figure 5A). Therefore, with $50 \mathrm{nM}$ siRNA, MO-based lipoplexes proved to be more efficient in the downregulation of eGFP than the commercial reagent tested. Gene silencing was not increased when higher charge ratios were used for transfection (data not shown).

Figure 5C and $\mathrm{D}$ show the results obtained by flow cytometry when H1299 eGFP cells were incubated with fluorescently labeled siRNA-lipoplexes at 37 and $4{ }^{\circ} \mathrm{C}$. In this experiment, cells were also treated with sodium azide as control. It is known that sodium azide inhibits oxidative phosphorylation and thus energy-dependent uptake by endocytosis. At $37{ }^{\circ} \mathrm{C}$ (Figure 5C), MO-based lipoplexes were more efficiently internalized than Lipofectamine RNAiMax, while no significant differences between the uptake of the four MO-based lipoplexes could be detected. Incubation of the cells at $4{ }^{\circ} \mathrm{C}$ or after sodium azide treatment almost completely inhibited lipoplex uptake. This result indicates that energydependent endocytosis is the primary route of cellular internalization. Nevertheless, there may be a small contribution by direct fusion with the plasma membrane for DODAB:MO, judging from the results in Figure 5C. In any case this is a minor effect compared to Lipofectamine RNAiMax, as seen by the percentage of positive cells $(22 \%)$ after sodium azide treatment (Figure 5C).

Although at a physiological temperature the percentage of positive cells was high for all the MO-based lipoplexes (Figure 5C), the mean fluorescence intensity observed (Figure 5D) was quite different. This indicates that the amount of internalized lipoplexes per cell was higher for DODAX:MO (2:1) than for DODAX:MO (1:2), though DODAB:MO lipoplexes were more internalized than DODAC:MO lipoplexes (for both DODAX:MO molar fractions).

It is well-known that an efficient siRNA delivery depends on several steps, including the encapsulation and protection of siRNA, cellular internalization of the siRNA-lipoplexes, or escape of the siRNA from the endosome into the cytoplasm. ${ }^{48}$ The nanocarrier structure can facilitate or hinder some of these aspects, with consequences for the final transfection efficiencies. The counterions $\mathrm{Cl}^{-}$and $\mathrm{Br}^{-}$have important effects on the selfassembling structures of DODAC:MO and DODAB:MO: DODAC:MO forms lamellar phases with less tight polar head groups, where $\mathrm{MO}$ can be better distributed when compared to DODAB bilayers; the more tightly packed head groups of $\mathrm{DODAB}$ hinder $\mathrm{MO}$ integration into the bilayers, resulting in the formation of MO-rich and DODAB-rich domains. Therefore, the counterions will influence the performance of DODAX:MO siRNA-lipoplexes at various levels. For instance, the surrounding medium has probably a different impact on DODAB:MO and DODAC:MO lipoplexes, due to the different structural organization of the liposomes (Figure 1 and Tables 1 and 2), altering the siRNA-lipoplex stability and/or resulting in uptake by distinct endocytic routes. In fact, DODAC:MO and DODAB:MO siRNA-lipoplexes were found to have different stabilities when dispersed in serum, with DODAC:MO lipoplexes releasing almost all of the siRNA content when in contact with serum, while DODAB:MO lipoplexes released less than $50 \%$ of the siRNA content (Supporting Information, Figure S4). The experiment was performed by incubating DODAX:MO (2:1) siRNA-lipoplexes with 50\% (v:v) serum (FBS), for $1 \mathrm{~h}$ at $37^{\circ} \mathrm{C}$, and the siRNA release determined by fluorescence fluctuation spectroscopy (FFS) technique as described before. ${ }^{49-52}$ The lower packed headgroup region of DODAC:MO siRNA-lipoplexes is responsible for this higher destabilization, because less stability is conferred to the siRNA entrapped between lamellas. siRNA is then more easily dissociated from the siRNA-lipoplexes by serum proteins. Additionally, decreased stability can be reflected in a less efficient internalization of DODAC:MO siRNA-lipoplexes by the cells, as observed in Figure 5D. Similar results have been reported for other lipoplexes, where highly packed and dense lamellar structures were found to be less destabilized by the binding of serum proteins, and higher transfection efficiencies were obtained. ${ }^{53}$

It is known that lipoplexes with a highly curved structure and high fluidity interact more readily with serum proteins. This fact can lead to aggregation and/or disintegration, compared with lipoplexes having stable lamellar structures. ${ }^{54,55}$ The phase and fluidity of the liposome bilayers are therefore important for the nanoparticle's stability and behavior when dispersed in complex fluids.

The siRNA-lipoplex cellular internalization can be influenced by the counterion at another level. The reduced headgroup area of $\mathrm{DODAB}$, that leads to the formation of less curved aggregates $^{36}$ (confirmed by the higher size of DODAB:MO 


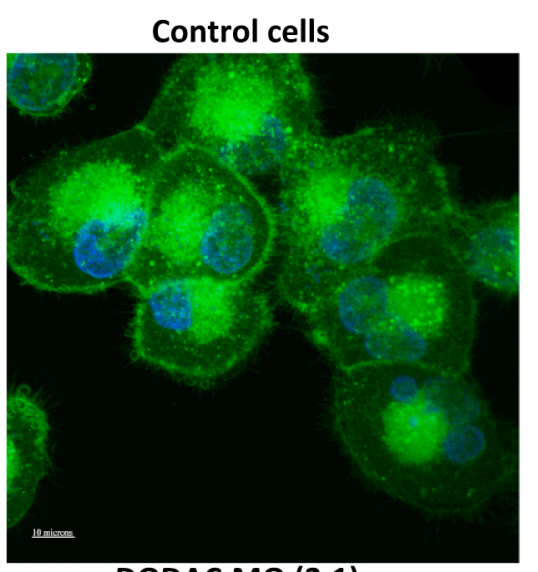

DODAC:MO (2:1)

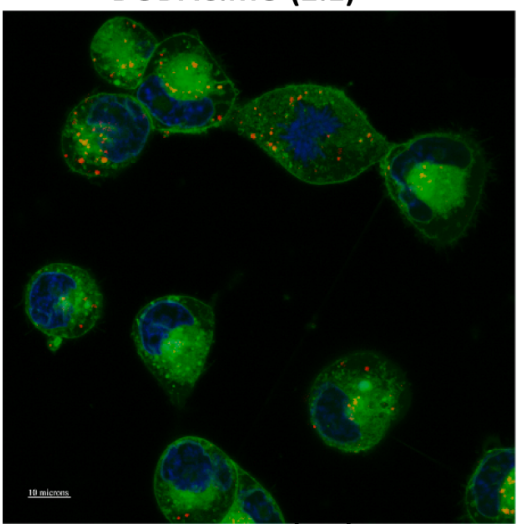

DODAC:MO (1:2)

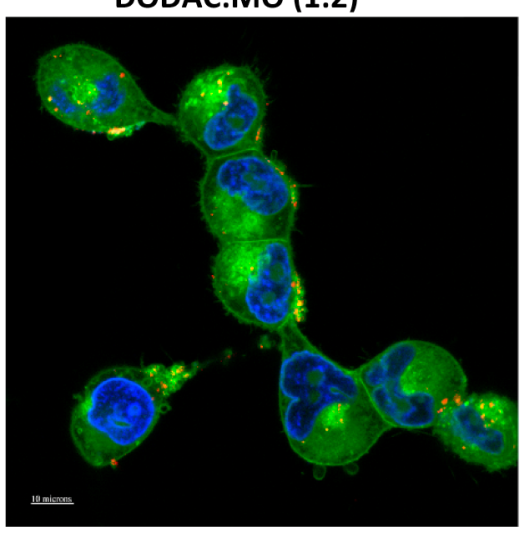

\section{Lipofectamine RNAiMax ${ }^{\circledast}$}

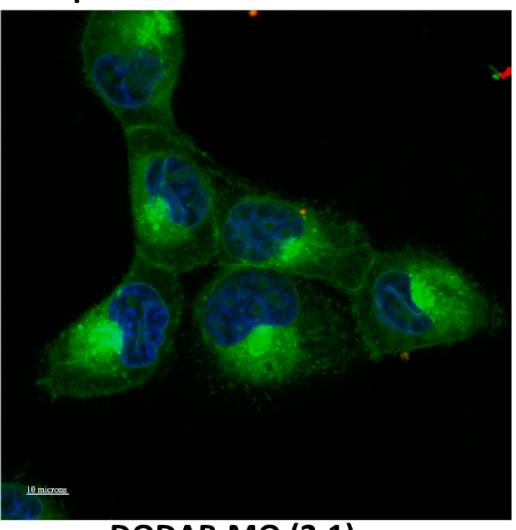

DODAB:MO (2:1)

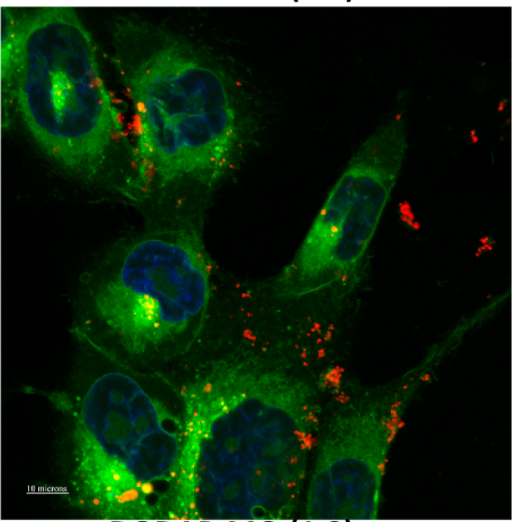

DODAB:MO (1:2)

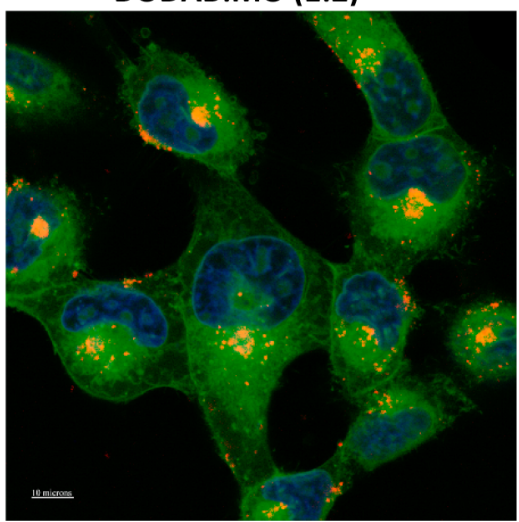

Figure 6. Cellular uptake of siRNA-lipoplexes. Confocal images of the intracellular distribution of Cy5-labeled siRNA-lipoplexes after $4 \mathrm{~h}$ incubation with $\mathrm{H} 1299$ wild-type cells. Scale bar $10 \mu \mathrm{m}$.

compared to DODAC:MO formulations (Figure 3)), can facilitate the adherence of the lipoplexes to the surfaces of the cells. $^{48}$ Another consequence of the different structural organization of DODAC and DODAB:MO liposomes is observed on their fusogenic ability. The better incorporation of MO within DODAC bilayers contributed to the better lipid mixing between the model membranes and liposomal membranes seen for DODAC-MO liposomes (Figure 4).

The poor performance of DODAC:MO lipoplexes can thus be a consequence of the properties of the membrane bilayers, and not solely due to lower internalization in comparison to DODAB:MO lipoplexes (Figure 5D), since several steps of the nanocarrier delivery process (siRNA-lipoplexes stability and siRNA protection, cellular internalization, or fusogenic ability) seem to be influenced by the presence of $\mathrm{Cl}^{-}$or $\mathrm{Br}$. Nevertheless, it has been shown that only a very limited number of siRNA molecules are required at the cytoplasm to induce a significant gene silencing. ${ }^{56-58}$ This result was observed for Lipofectamine RNAiMax, for which only a small fraction of siRNA introduced into the cell cytoplasm was sufficient to induce eGFP downregulation in almost 60\% (50 $\mathrm{nM}$ siRNA), supporting it as a very efficient siRNA carrier system. $^{59}$

The results for DODAB:MO liposomes give further support to the fact that $\mathrm{MO}$ has important effects on the properties of liposomes and on the in vitro performance of the nanocarriers. A similar number of positive cells for DODAB:MO (2:1) and (1:2) nanoparticles (Figure 5C) was observed, but less siRNA was internalized by cells treated with DODAB:MO (1:2) lipoplexes (Figure 5D). Nevertheless, the same silencing efficiency was observed for both formulations (Figure 5B). This suggests that MO played a favorable role in the 
transfection process, either by promoting a different internalization route for the two types of siRNA-lipoplexes, or by determining an enhanced escape of siRNA from endosomes.

3.4. Confocal Laser Scanning Microscopy (CLSM). Intracellular uptake of siRNA-lipoplexes by H1299 wild-type cells was also visualized by CLSM (Figure 6). Fluorescent Cy5labeled siRNA (red) was used to track the lipoplexes; cell nuclei were stained with Hoechst 33342 dye (blue) and endolysosomal compartments with the LysoSensor Green dye.

Figure 6 shows that all four MO-based labeled lipoplexes (DODAC:MO (2:1), DODAB:MO (2:1), DODAC:MO (1:2), and DODAB:MO (1:2) siRNA-lipoplexes) were taken up by the cells after $4 \mathrm{~h}$ incubation, even though at different extents.

A clear difference in the internalization of DODAC:MO and DODAB:MO lipoplexes was observed. DODAB:MO siRNAlipoplexes were internalized at a higher extent than DODAC:MO lipoplexes, which corroborates the flow cytometry results. siRNA-lipoplexes are distributed throughout the cytoplasm of the cells, but a conclusion about the colocalization with endo/lysosomal compartments is not possible.

The uptake observed for Lipofectamine RNAiMax and MObased formulations was strikingly different. A very low amount of labeled siRNA lipoplexes is seen for Lipofectamine RNAiMax compared to the other formulations. Once again the differences observed are in agreement with the flow cytometry (Figure 5C and D).

3.5. Comparison of $\mathrm{MO}$ and DOPE as Helper Lipids. MO-based siRNA-lipoplexes were compared with lipoplexes prepared with the well-established helper lipid DOPE, in terms of cytotoxicity, transfection efficiency, and internalization (Figure 7). As the results presented so far indicate that DODAB:MO liposomes are more promising for siRNA delivery than DODAC:MO liposomes, comparison was made with only DODAB:MO $(2: 1)$ liposomes.

No significant differences were evident on the gene silencing induced by DODAB:MO (2:1), DODAB:DOPE (2:1), and neat DODAB lipoplexes $(67 \%, 63 \%$, and $73 \%$ eGFP downregulation, respectively, on Figure $7 \mathrm{~B}$ ). Nevertheless, DODAB:MO (2:1) lipoplexes caused the lowest cytotoxicity in H1299 eGFP cells (Figure 7A): 95\% cell survival compared to $80 \%$ and $70 \%$ for DODAB:DOPE $(2: 1)$ and the DODAB lipoplexes, respectively. Thus, MO was able to decrease the toxicity without compromising the efficiency of lipofection.

Regarding the internalization, with DODAB:MO (2:1) and neat DODAB, lipoplexes were taken up by $90 \%$ of the cells at $37{ }^{\circ} \mathrm{C}$, while with DODAB:DOPE $(2: 1)$ only $50 \%$ of cells internalized lipoplexes. The same trend was observed for the mean fluorescence intensity results. Sodium azide inhibits oxidative phosphorylation and thus energy-dependent uptake by endocytosis. The sodium azide uptake inhibition was more efficient for DODAB:DOPE $(2: 1)$ and neat DODAB formulations than for DODAB:MO (2:1) lipoplexes.

The uptake of the DODAB:DOPE formulation was very low compared to the other nanocarrier formulations, although the transfection efficiency was not negatively affected, which suggests a very efficient intracellular delivery mechanism for this formulation as already observed for Lipofectamine RNAiMax.

\section{CONCLUSIONS}

The work described here has important implications for the design of siRNA-lipoplex delivery systems. The combination of the nanocarriers' components must be carefully optimized, as it

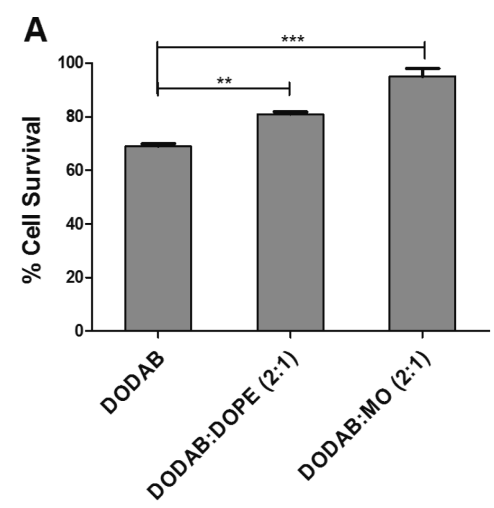

B
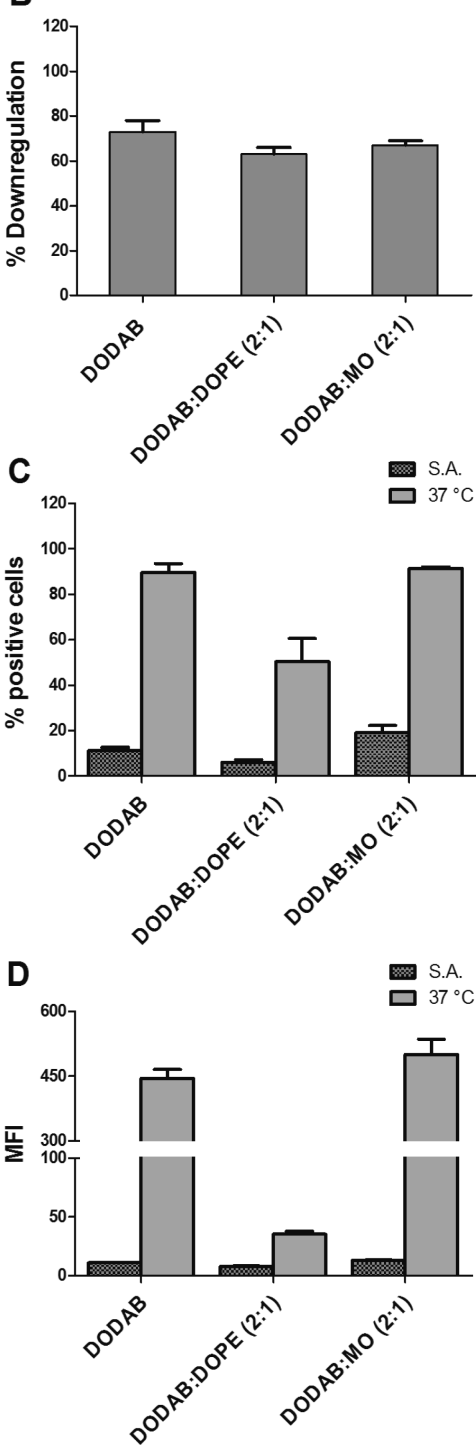

Figure 7. Effect of MO or DOPE on the cytotoxicity (A), transfection efficiency (B), and cellular internalization (C and D) of siRNAlipoplexes. Lipoplexes were prepared with $10 \mathrm{nM}$ siRNA for the transfection experiment and with $50 \mathrm{nM}$ siRNA for the toxicity and uptake experiments. S.A. - Sodium Azide. MFI - Mean Fluorescence Intensity. Results are expressed as mean $\pm \mathrm{SD}$. The ANOVA statistical test was performed, followed by a Dunnett's multiple comparison test. $*_{p}<0.05, * * p<0.01$, and $* * * p<0.005$.

was clear that the liposomal structural organization and membrane properties were highly dependent on the specific 
mixture between the neutral lipid $\mathrm{MO}$ and the cationic lipid DODAC or DODAB. A model for the structural organization of DODAX:MO nanocarriers was proposed, showing a different lipid organization depending on the MO content. Changing the counterion $\mathrm{Cl}^{-}$by $\mathrm{Br}^{-}$altered the nanocarriers' properties in such a way that defined the silencing efficiency. The observed variations in structural properties of the four tested formulations resulted not only in different levels of internalization, but also in different transfection activities. The uptake of the lipoplexes is predominantly occurring by an active process, endocytosis being the main internalization route for MO-based nanocarriers. Taking into consideration all the results, we conclude that DODAB:MO liposomes were found to be better siRNA-nanocarriers than DODAC:MO liposomes, as they induce lower cytotoxicity, are better internalized, and promote higher gene silencing in H1299 eGFP cells.

This work suggests a new formulation for siRNA delivery, composed of the neutral lipid $\mathrm{MO}$ and the cationic lipid DODAB, which is currently undergoing further optimization for systemic siRNA delivery.

\section{ASSOCIATED CONTENT}

\section{S Supporting Information}

Fluorescence and emission spectra of NBD-DHPE and RhoDHPE, additional cytotoxicity results, and serum stability analysis. This material is available free of charge via the Internet at http://pubs.acs.org.

\section{AUTHOR INFORMATION}

\section{Corresponding Author}

*E-mail: beta@fisica.uminho.pt. Tel: +351 253 604325. Fax: +351253604061.

\section{Notes}

The authors declare the following competing financial interest(s): The University of Minho, M.E.C.D.R.O., and A.C.G. have filed patent applications of Portuguese Patent PT104158 (2011), European Patent EP2335687 A2 (2011), and International Patent WO2010/020935 A2 (2010), respectively.

\section{ACKNOWLEDGMENTS}

This work was supported by FEDER through POFC COMPETE and by national funds from FCT through the projects PEst-C/BIA/UI4050/2011 (CBMA), PEst-C/FIS/ UI0607/2011 (CFUM), and PTDC/QUI/69795/2006, while Ana Oliveira holds scholarship SFRH/BD/68588/2010. Eloi Feitosa thanks FAPESP (2011/03566-0) and CNPq (303030/ 2012-7), and Renata D. Adati thanks FAPESP for scholarship (2011/07414-0). K. Raemdonck is a postdoctoral fellow of the Research Foundation - Flanders (FWO-Vlaanderen). We acknowledge NanoDelivery-I\&D em Bionanotecnologia, Lda. for access to their equipment.

\section{ABBREVIATIONS}

CLSM, confocal laser scanning microscopy; DLS, dynamic light scattering; DODAB, dioctadecyldimethylammonium bromide; DODAC, dioctadecyldimethylammonium chloride; DOPC, 1,2-dioleoyl-sn-glycero-3-phosphocholine; DOPE, 1,2-dioleyl3-phosphatidylethanolamine; DOPS, 1,2-dioleoyl-sn-glycero-3phospho-L-serine; DSC, differential scanning calorimetry; FRET, fluorescence resonance energy transfer; MO, 1monooleoyl-rac-glycerol, monoolein; $\zeta$-potential, zeta potential

\section{REFERENCES}

(1) Fire, A.; Xu, S.; Montgomery, M. K.; Kostas, S. A.; Driver, S. E.; Mello, C. C. Potent and Specific Genetic Interference by DoubleStranded RNA in Caenorhabditis elegans. Nature 1998, 391, 806-811.

(2) Elbashir, S. M.; Harborth, J.; Lendeckel, W.; Yalcin, A.; Weber, K.; Tuschl, T. Duplexes of 21-Nucleotide RNAs Mediate RNA Interference in Cultured Mammalian Cells. Nature 2001, 411, 494498.

(3) Oh, Y.-K.; Park, T. G. siRNA Delivery Systems for Cancer Treatment. Adv. Drug Delivery Rev. 2009, 61, 850-862.

(4) Tseng, Y.-C.; Mozumdar, S.; Huang, L. Lipid-Based Systemic Delivery of siRNA. Adv. Drug Delivery Rev. 2009, 61, 721-731.

(5) Whitehead, K. A.; Langer, R.; Anderson, D. G. Knocking Down Barriers: Advances in siRNA Delivery. Nat. Rev. Drug Discovery 2009, $8,129-138$.

(6) Wang, J.; Lu, Z.; Wientjes, M. G.; Au, J. L.-S. Delivery of siRNA Therapeutics: Barriers and Carriers. AAPS J. 2010, 12, 492-503.

(7) Akinc, A.; Zumbuehl, A.; Goldberg, M.; Leshchiner, E. S.; Busini, V.; Hossain, N.; Bacallado, S. A.; Nguyen, D. N.; Fuller, J.; Alvarez, R; Borodovsky, A.; Borland, T.; Constien, R.; Fougerolles, A.; de Dorkin, J. R.; Jayaprakash, K. N.; Jayaraman, M.; John, M.; Koteliansky, V.; Manoharan, M.; Nechev, L.; Qin, J.; Racie, T.; Raitcheva, D.; Rajeev, K. G.; Sah, D. W. Y.; Soutschek, J.; Toudjarska, I.; Vornlocher, H.-P.; Zimmermann, T. S.; Langer, R.; Anderson, D. G. A Combinatorial Library of Lipid-Like Materials for Delivery of RNAi Therapeutics. Nat. Biotechnol. 2008, 26, 561-569.

(8) Felgner, P. L.; Gadek, T. R.; Holm, M.; Roman, R.; Chan, H. W.; Wenz, M.; Northrop, J. P.; Ringold, G. M.; Danielsen, M. Lipofection: a Highly Efficient, Lipid-Mediated DNA-Transfection Procedure. Proc. Natl. Acad. Sci. U. S. A. 1987, 84, 7413-7417.

(9) Wasungu, L.; Hoekstra, D. Cationic Lipids, Lipoplexes and Intracellular Delivery of Genes. J. Controlled Release 2006, 116, 255264.

(10) Zhang, S.; Xu, Y.; Wang, B.; Qiao, W.; Liu, D.; Li, Z. Cationic Compounds used in Lipoplexes and Polyplexes for Gene Delivery. J. Controlled Release 2004, 100, 165-180.

(11) Kundu, A. K.; Chandra, P. K.; Hazari, S.; Pramar, Y. V.; Dash, S.; Mandal, T. K. Development and Optimization of Nanosomal Formulations for siRNA Delivery to the Liver. Eur. J. Pharm. Biopharm. 2012, 80, 257-267.

(12) Zuhorn, I. S.; Bakowsky, U.; Polushkin, E.; Visser, W. H.; Stuart, M. C. A.; Engberts, J. B. F. N.; Hoekstra, D. Nonbilayer Phase of Lipoplex-Membrane Mixture Determines Endosomal Escape of Genetic Cargo and Transfection Efficiency. Mol. Ther. 2005, 11, 801-810.

(13) Varkouhi, A. K.; Scholte, M.; Storm, G.; Haisma, H. J. Endosomal Escape Pathways for Delivery of Biologicals. J. Controlled Release 2011, 151, 220-228.

(14) Koynova, R.; Wang, L.; Macdonald, R. C. An Intracellular Lamellar - Nonlamellar Phase Transition Rationalizes the Superior Performance of Some Cationic Lipid Transfection Agents. Proc. Natl. Acad. Sci. U. S. A. 2006, 103, 14373-14378.

(15) Zelphati, O.; Szoka, F. C. Mechanism of Oligonucleotide Release from Cationic Liposomes. Proc. Natl. Acad. Sci. U. S. A. 1996, 93, 11493-11498.

(16) Obata, Y.; Tajima, S.; Takeoka, S. Evaluation of pH-Responsive Liposomes Containing Amino Acid-Based Zwitterionic Lipids for Improving Intracellular Drug Delivery In Vitro and In Vivo. J. Controlled Release 2010, 142, 267-276.

(17) Obata, Y.; Saito, S.; Takeda, N.; Takeoka, S. Plasmid DNA Encapsulating Liposomes: Effect of a Spacer Between the Cationic Head Group and Hydrophobic Moieties of the Lipids on Gene Expression Efficiency. Biochim. Biophys. Acta 2009, 1788, 1148-1158.

(18) Hyvönen, Z.; Hämäläinen, V.; Ruponen, M.; Lucas, B.; Rejman, J.; Vercauteren, D.; Demeester, J.; Smedt, S.; De Braeckmans, K. Elucidating the Pre- and Post-Nuclear Intracellular Processing of 1,4Dihydropyridine Based Gene Delivery Carriers. J. Controlled Release 2012, 162, 167-175. 
(19) Siegel, D. P.; Epand, R. M. The Mechanism of Lamellar-toInverted Hexagonal Phase Transitions in Phosphatidylethanolamine: Implications for Membrane Fusion Mechanisms. Biophys. J. 1997, 73, 3089-3111.

(20) Wang, L.; MacDonald, R. C. New Strategy for Transfection: Mixtures of Medium-Chain and Long-Chain Cationic Lipids Synergistically Enhance Transfection. Gene Ther. 2004, 11, 13581362.

(21) Uddin, S. N. Cationic Lipids used in Non-Viral Gene Delivery Systems. Biotechnol. Mol. Biol. Rev. 2007, 2, 58-67.

(22) Bhattacharya, S.; Bajaj, A. Advances in Gene Delivery Through Molecular Design of Cationic Lipids. Chem. Commun. (Cambridge, U. K.) 2009, 4632-4656.

(23) Feitosa, E.; Barreleiro, P. C. A.; Olofsson, G. Phase Transition in Dioctadecyldimethylammonium Bromide and Chloride Vesicles Prepared by Different Methods. Chem. Phys. Lipids 2000, 105, 201213.

(24) Feitosa, E.; Alves, F. R. The Role of Counterion on the Thermotropic Phase Behavior of DODAB and DODAC Vesicles. Chem. Phys. Lipids 2008, 156, 13-16.

(25) Feitosa, E.; Alves, F. R.; Castanheira, E. M. S.; Real Oliveira, M. E. C. D. DODAB and DODAC Bilayer-Like Aggregates in the Micromolar Surfactant Concentration Domain. Colloid Polym. Sci. 2009, 287, 591-599.

(26) Silva, J. P. N.; Oliveira, A. C. N.; Casal, M. P. P. A.; Gomes, A. C.; Coutinho, P. J. G.; Coutinho, O. P.; Real Oliveira, M. E. C. D. DODAB:Monoolein-Based Lipoplexes as Non-Viral Vectors for Transfection of Mammalian Cells. Biochim. Biophys. Acta 2011, 1808, 2440-2449.

(27) Silva, J. P. S.; Oliveira, A. C. N.; Gomes, A. C.; Real Oliveira, M. E. C. D. In Cell Interaction; Gowder, S., Ed.; InTech: Rijeka, Croatia, 2012; Chapter 10, pp 245-272.

(28) Oliveira, I. M. S. C.; Silva, J. P. N.; Feitosa, E.; Marques, E. F.; Castanheira, E. M. S.; Real Oliveira, M. E. C. D. Aggregation Behavior of Aqueous Dioctadecyldimethylammonium Bromide/Monoolein Mixtures: a Multitechnique Investigation on the Influence of Composition and Temperature. J. Colloid Interface Sci. 2012, 374, 206-217.

(29) Luzzati, V. Biological Significance of Lipid Polymorphism: the Cubic Phases. Curr. Opin. Struct. Biol. 1997, 7, 661-668.

(30) Leal, C.; Bouxsein, N. F.; Ewert, K. K.; Safinya, C. R. Highly Efficient Gene Silencing Activity of siRNA Embedded in a Nanostructured Gyroid Cubic Lipid Matrix. J. Am. Chem. Soc. 2010, 132, 16841-16847.

(31) Valeur, B. Molecular Fluorescence: Principles and Applications; Wiley-VCH Verlag GmbH: Weinheim, 2001.

(32) Struck, D. K.; Hoekstra, D.; Pagano, R. E. Use of Resonance Energy Transfer to Monitor Membrane Fusion. Biochemistry 1981, 20, 4093-4099.

(33) Savva, M.; Chen, P.; Aljaberi, A.; Selvi, B.; Spelios, M. In Vitro Lipofection with Novel Asymmetric Series of 1,2-Dialkoylamidopropane-Based Cytofectins Containing Single Symmetric Bis-(2-Dimethylaminoethane) Polar Headgroups. Bioconjugate Chem. 2005, 16, $1411-1422$.

(34) Nascimento, D. B.; Rapuano, R.; Lessa, M. M.; CarmonaRibeiro, A. M. Counterion Effects on Properties of Cationic Vesicles. Langmuir 1998, 14, 7387-7391.

(35) McGrath, K. M. Phase Behavior of Dodecyltrimethylammonium Bromide/Water Mixtures. Langmuir 1995, 11, 1835-1839.

(36) Liu, C. K.; Warr, G. G. Hexagonal Closest-Packed Spheres Liquid Crystalline Phases Stabilized by Strongly Hydrated Counterions. Soft Matter 2014, 10, 83-87.

(37) Hungerford, G.; Castanheira, E. M. S.; Baptista, A. L. F.; Coutinho, P. J. G.; Real Oliveira, M. E. C. D. Domain Formation in DODAB-Cholesterol Mixed Systems Monitored via Nile Red Anisotropy. J. Fluoresc. 2005, 15, 835-840.

(38) Blandamer, M. J.; Briggs, B.; Cullis, P. M.; Rawlings, B. J.; Engberts, J. B. F. N. Vesicle-Cholesterol Interactions: Effects of Added Cholesterol on Gel-to-Liquid Crystal Transitions in a Phospholipid
Membrane and Five Dialkyl-Based Vesicles as Monitored using DSC Phys. Chem. Chem. Phys. 2003, 5, 5309-5312.

(39) Kulkarni, C. V.; Wachter, W.; Iglesias-Salto, G.; Engelskirchen, S.; Ahualli, S. Monoolein: a Magic Lipid? Phys. Chem. Chem. Phys. 2011, 13, 3004-3021.

(40) Leal, C.; Ewert, K. J.; Bouxsein, N. F.; Shirazi, R. S.; Li, Y.; Safinya, C. R. Stacking of Short DNA Induces the Gyroid Cubic-toInverted Hexagonal Phase Transition in Lipid-DNA Complexes. Soft Matter 2013, 9, 795-804.

(41) Bilalov, A.; Elsing, J.; Haas, E.; Schmidt, C.; Olsson, U. Embedding DNA in Surfactant Mesophases: The Phase Diagram of the Ternary System Dodecyltrimethylammonium-DNA/Monoolein/ Water in Comparison to the DNA-Free Analogue. J. Colloid Interface Sci. 2013, 394, 360-367.

(42) Leal, C.; Sandström, D.; Nevsten, P.; Topgaard, D. Local and Translational Dynamics in DNA-Lipid Assemblies Monitored by Solid-State and Diffusion NMR. Biochim. Biophys. Acta 2008, 1778, 214-228.

(43) Sagalowicz, L.; Mezzenga, R.; Leser, M. E. Investigating Reversed Liquid Crystalline Mesophases. Curr. Opin. Colloid Interface Sci. 2006, 11, 224-229.

(44) Braet, F.; Wisse, E. Structural and Functional Aspects of Liver Sinusoidal Endothelial Cell Fenestrae: a Review. Comp. Hepatol. 2002, $1,1-17$.

(45) Yuan, F.; Dellian, M.; Fukumura, D.; Leunig, M.; Berk, D. A.; Torchilin, V. P.; Jain, R. K. Vascular Permeability in a Human Tumor Xenograft: Molecular Size Dependence and Cutoff Size. Cancer Res. 1995, 55, 3752-3756.

(46) Dominska, M.; Dykxhoorn, D. M. Breaking Down the Barriers: siRNA Delivery and Endosome Escape. J. Cell Sci. 2010, 123, 11831189.

(47) Madeira, C.; Loura, L. M. S.; Aires-Barros, M. R.; Prieto, M. Fluorescence Methods for Lipoplex Characterization. Biochim. Biophys. Acta 2011, 1808, 2694-2705.

(48) Ma, B.; Zhang, S.; Jiang, H.; Zhao, B.; Lv, H. Lipoplex Morphologies and their Influences on Transfection Efficiency in Gene Delivery. J. Controlled Release 2007, 123, 184-194.

(49) Buyens, K.; Lucas, B.; Raemdonck, K.; Braeckmans, K.; Vercammen, J.; Hendrix, J.; Engelborghs, Y.; De Smedt, S. C.; Sanders, N. N. A Fast and Sensitive Method for Measuring the Integrity of siRNA-Carrier Complexes in Full Human Serum. J. Controlled Release 2008, 126, 67-76.

(50) Buyens, K.; Demeester, J.; De Smedt, S. S.; Sanders, N. N. Elucidating the Encapsulation of Short Interfering RNA in PEGylated Cationic Liposomes. Langmuir 2009, 25, 4886-4891.

(51) Naeye, B.; Raemdonck, K.; Remaut, K.; Sproat, B.; Demeester, J.; De Smedt, S. C. PEGylation of Biodegradable Dextran Nanogels for siRNA Delivery. Eur. J. Pharm. Sci. 2010, 40, 342-351.

(52) Naeye, B.; Deschout, H.; Röding, M.; Rudemo, M.; Delanghe, J.; Devreese, K.; Demeester, J.; Braeckmans, K.; De Smedt, S. C.; Raemdonck, K. Hemocompatibility of siRNA Loaded Dextran Nanogels. Biomaterials 2011, 32, 9120-9127.

(53) Llères, D.; Weibel, J.-M.; Heissler, D.; Zuber, G.; Duportail, G.; Mély, Y. Dependence of the Cellular Internalization and Transfection Efficiency on the Structure and Physicochemical Properties of Cationic Detergent/DNA/Liposomes. J. Gene Med. 2004, 6, 415-428.

(54) Caracciolo, G.; Callipo, L.; De Sanctis, S. C.; Cavaliere, C.; Pozzi, D.; Laganà, A. Surface Adsorption of Protein Corona Controls the Cell Internalization Mechanism of DC-Chol-DOPE/DNA Lipoplexes in Serum. Biochim. Biophys. Acta 2010, 1798, 536-543.

(55) Li, S.; Tseng, W. C.; Stolz, D. B.; Wu, S.-P.; Watkins, S. C.; Huang, L. Dynamic Changes in the Characteristics of Cationic Lipidic Vectors after Exposure to Mouse Serum: Implications for Intravenous Lipofection. Gene Ther. 1999, 6, 585-594.

(56) Detzer, A.; Overhoff, M.; Wünsche, W.; Rompf, M.; Turner, J. J.; Ivanova, G.; Gait, M. J.; Sczakiel, G. Increased RNAi is Related to Intracellular Release of siRNA via a Covalently Attached Signal Peptide. RNA 2009, 15, 1-10. 
(57) Veldhoen, S.; Laufer, S. D.; Trampe, A.; Restle, T. Cellular Delivery of Small Interfering RNA by a Non-Covalently Attached CellPenetrating Peptide: Quantitative Analysis of Uptake and Biological Effect. Nucleic Acids Res. 2006, 34, 6561-6573.

(58) Lu, J. J.; Langer, R.; Chen, J. A Novel Mechanism is Involved in Cationic Lipid-Mediated Functional siRNA Delivery. Mol. Pharmaceutics 2009, 6, 763-771.

(59) Zhao, M.; Yang, H.; Jiang, X.; Zhou, W.; Zhu, B.; Zeng, Y.; Yao, K.; Ren, C. Lipofectamine RNAiMAX: an Efficient siRNA Transfection Reagent in Human Embryonic Stem Cells. Mol. Biotechnol. 2008, 40, 19-26. 